\title{
Combustion Optimization thru Statics Modeling OF Engine Calibration Parameters to Minimize Specific Fuel Consumption for MAR-I STANDARDS EMISSIONS CYCLE
}

\author{
Flávio Augusto Levoto Cintra ${ }^{1}$, André Sperl ${ }^{1.1}$ e Rafael Akira Konikosita ${ }^{1.2}$ \\ MWM Motores Diesel ${ }^{1}$ \\ E-mails: flavio.cintra@ navistar.com.br, andre.sperl@navistar.com.br, \\ rafael.konikosita@ navistar.com.br
}

\begin{abstract}
The competitiveness of the Brazilian market and the adverse economic scenario brought to agricultural producers and industry entrepreneurs the need and growing dependence on Government incentives such as FINAME for modernization and updating of their machinery and equipment, on the other hand the legislative requirements - as emissions legislation MAR-I for agricultural and industrial machines-promote the search for increased efficiency in internal combustion engines in terms of performance, emissions and fuel consumption. This scenario directs the auto industry to develop and use statistical tools that assist in the calibration process of these new engines, reducing time, cost and improving the quality of the product, making it the most attractive in cost-benefit terms to the final customer. This work aims to present a methodology for use of these statistical tools to increase the efficiency of the calibration and combustion optimization process of diesel engines, developing combustion capable of meeting the requirements in the MAR-I emissions legislation with the best fuel consumption that the engine can provide.
\end{abstract}

\section{INTRODUCTION}

The market of Off-Road vehicles went thru a new challenge the MAR-I emissions legislation in force since January 2015, the diesel engines that equip these vehicles should meet performance desired by customer and emissions required by MAR-I legislation.

In July 2011, CONAMA adopted Resolution 433/2011 limiting exhaust emissions and noise from new construction and farm machinery [6]. Referred to as PROCONVE MAR-I, it is the first legislation to regulate emissions from non-road mobile machinery in Brazil. It sets limits equivalent to USA Tier 3 and EU Stage III A for non-road diesel engine emissions. MAR-I emission limits are phased in from 2015 to 2019. The implementation dates depend on the power category and type of machinery (construction or farm), as shown in Table 1. Noise emission limits apply from 2015 for certain types of construction machinery with engines rated below $500 \mathrm{~kW}$. [1] 


\begin{tabular}{|c|c|c|c|c|c|}
\hline Rated Power & \multicolumn{2}{|c|}{ Date } & $\mathrm{CO}$ & $\mathrm{NO}_{\mathrm{x}}+\mathrm{HC}$ & PM \\
\hline$k W$ & Construction & Farming & \multicolumn{3}{|c|}{$g / k W h$} \\
\hline $130 \leq P \leq 560$ & 2015.01 & 2017.01 & 3.5 & 4.0 & 0.2 \\
\hline $75 \leq P<130$ & 2015.01 & 2017.01 & 5.0 & 4.0 & 0.3 \\
\hline $37 \leq P<75$ & 2015.01 & 2019.01 & 5.0 & 4.7 & 0.4 \\
\hline $19 \leq P<37$ & 2017.01 & 2019.01 & 5.5 & 7.5 & 0.6 \\
\hline
\end{tabular}

Table 1: MAR-I Emission Standards for Off-Road Diesel Engines [1]

For MAR-I emissions limits, emissions are measured in accordance with ISO 8178-1. The ISO $8178-1$ is an international standard for exhaust emission measurement from a number of non-road engine applications [5]. It is used for emission certification and/or type approval testing in many countries, including the United States, European Union and Japan [1]. Depending on the legislation, the cycle can be defined by reference to the ISO 8178-1 standard, as the case in Brazil.

The ISO 8178-1 includes a collection of steady-state engine dynamometer test cycles (designated as type C1, C2, D1, etc.) designed for different classes of engines and equipment. Each of these cycles represents a sequence of several steady-state modes with different weighting factors [1].

The ISO 8178-1 test cycle, or C1 and C2 types, are also referred to as the Non-Road Steady Cycle, NRSC, this in particular applied for MAR-I emissions tests. This specific engine operating modes for MAR-I emissions evaluation and their weighting factors, the $\mathrm{C} 1$ and $\mathrm{C} 2$ types of ISO 8178-1 test cycles are listed in Table 2. In Table 2 note that the intermediated speed according to the standard is the torque speed of the engine and the rated speed is the maximum power speed of the engine.

\begin{tabular}{|c|c|c|c|c|c|c|c|c|c|c|c|}
\hline Mode number & 1 & 2 & 3 & 4 & 5 & 6 & 7 & 8 & 9 & 10 & 11 \\
\hline Torque, $\%$ & 100 & 75 & 50 & 25 & 10 & 100 & 75 & 50 & 25 & 10 & 0 \\
\hline Speed & \multicolumn{5}{|c|}{ Rated speed } & \multicolumn{5}{|c|}{ Intermediate speed } & $\begin{array}{l}\text { Low } \\
\text { idle }\end{array}$ \\
\hline \multicolumn{12}{|l|}{ Off-road vehicles } \\
\hline Type C1 & 0.15 & 0.15 & 0.15 & - & 0.10 & 0.10 & 0.10 & 0.10 & - & - & 0.15 \\
\hline Type C2 & - & - & - & 0.06 & - & 0.02 & 0.05 & 0.32 & 0.30 & 0.10 & 0.15 \\
\hline
\end{tabular}

Table 2: MAR-I Emission Standards for Off-Road Diesel Engines [1]

To achieve this performance and emissions targets some statistical tools to generate engine models that can be used are presented in this work.

One of the best tools to aid combustion development and calibration in Diesel engines is design of experiments (DoE) with its increasing application in the last years. With the data gathered in DoE some models of the engine combustion can be generated using specific software using Matlab platform.

Gathering the information from emissions standard MAR-I, test procedures content of ISO8178-1 and DoE methodology to generate combustion models of the diesel engine under development, is possible to break through the traditional barriers of development using diesel combustion calibration knowledge and tools to create a diesel engine calibration with the best fuel consumption within the limits emission from MAR- I, all within an ideal development 
time combustion without jeopardizing the delivery of the new engine developed, to the final customer.

\section{BACKGROUND}

\subsection{Motivation}

\subsubsection{Goal is to improve our competitiveness through}

- Reduction of extensive test cell time required to develop engine calibration;

- Generation of truly optimal calibration in some pre-defined sense (such as minimum BSFC).

\subsubsection{Means to achieve goal}

- Systematic approach to generate engine calibration;

- Extract the most information about the engine behavior with the least amount of test data;

- Use mathematically sound optimization techniques to determine calibration.

\subsubsection{Tool}

- MATLAB is the chosen tool due to its computing power (required to handle large scale problems) and its built-in statistical and optimization functionality.

\subsubsection{Roles and Responsibilities of Advanced Analysis}

- Develop methodology (calibration and optimization techniques);

- Develop data-processing automation tools to enhance efficiency;

- Transfer developed techniques to engine calibration testing groups;

- Continuously cooperate with testing groups to build performance / emissions DoE database for future virtual engine calibration work.

\subsubsection{Maximum information out of test data}

- Determine boundary of achievable NOx / PM region;

- Minimum BSFC surface and corresponding calibration parameters (factors) on NOx / PM domain;

- Understand factor behavior for future DoE designs.
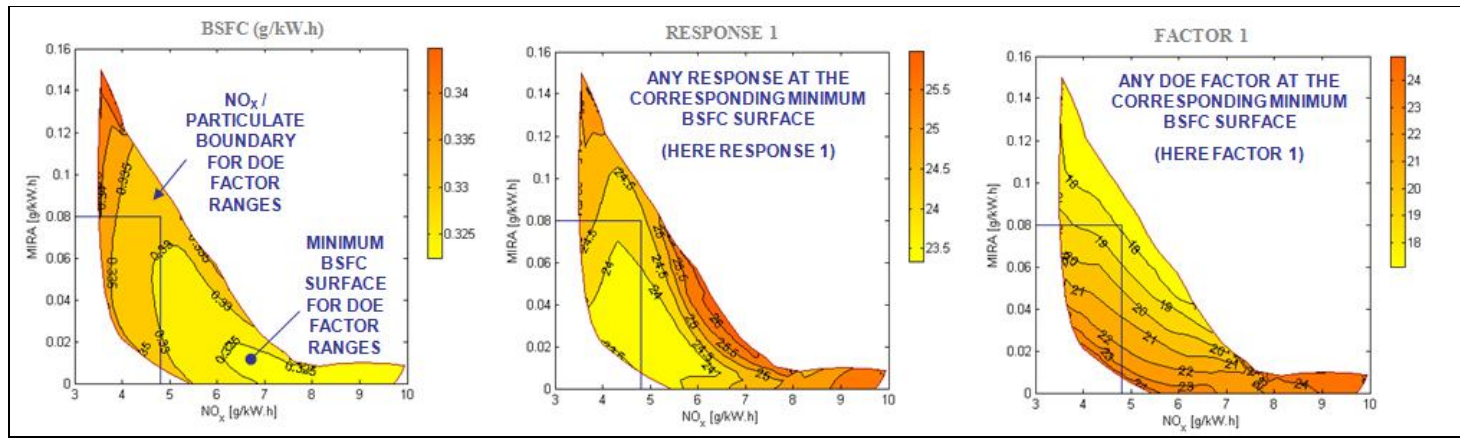

Figure 1: Process output to determine boundary of achievable NOx / PM region.

\subsubsection{Truly optimal calibration}


Calibration is generated in optimal sense. For example, minimizing BSFC for a given road cycle, while meeting steady state 8-Mode legal emissions.

How much transient calibration can be done with such approach?

- Fast turn-around times for calibration tables with adjusted constraints for transient response.

- Apply methodology to transient DoE testing.

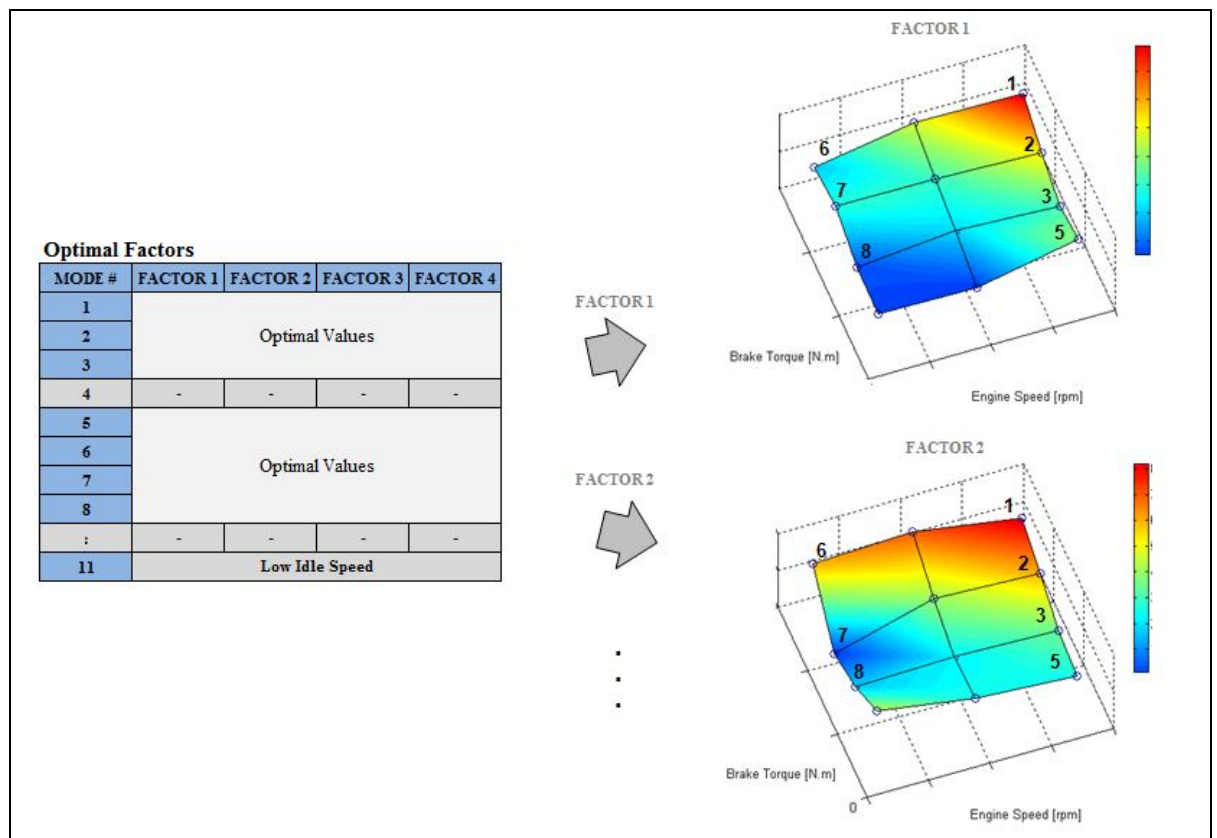

Figure 2: Truly optimal calibration.

\subsection{Typical off-road driving cycle}

As part of the cycle analysis of the diesel engine on its several off-road applications, many work cycles have been measured in recent years on different types of machines. Comparing these work cycles, we have an average distribution of engine speed, as shown in the Figures 3, 4 and 5 below.

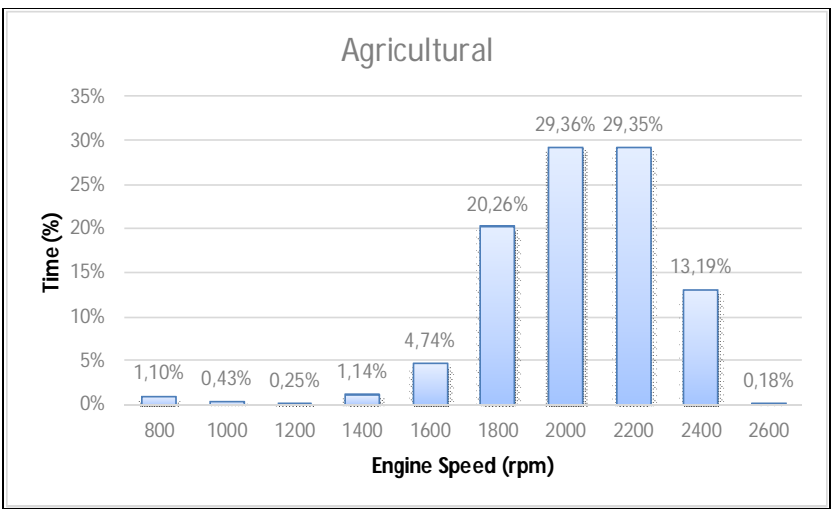

Figure 3: Typical distribution of agricultural tractors. 


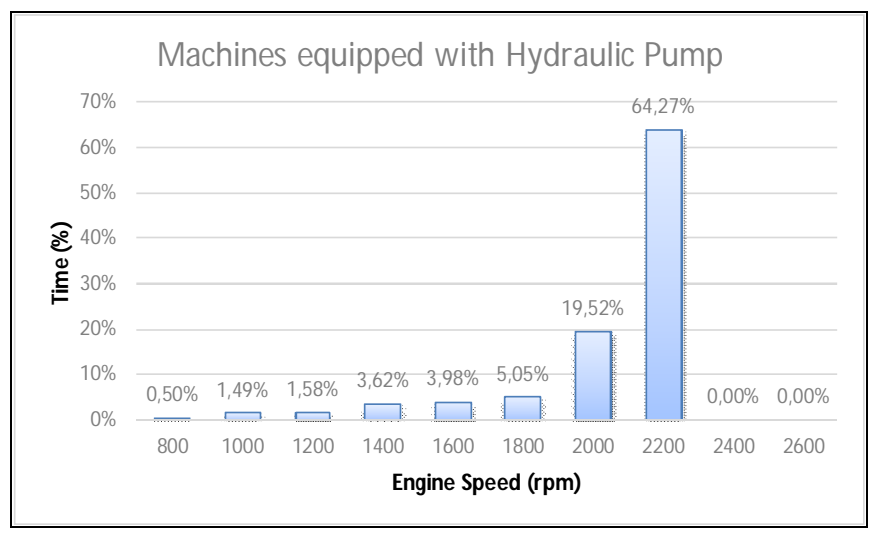

Figure 4: Typical average distribution of machines equipped with hydraulic pump.

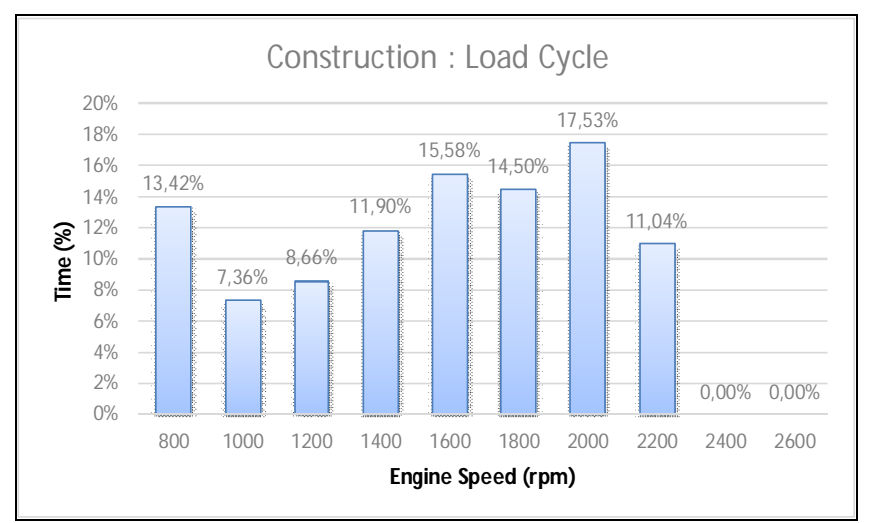

Figure 5: Typical average distribution employed in machines with loading ability.

Figure 3 includes agricultural tractors, with different types of implements. The engine speed presents some variation between these implements, but on average they have a very similar engine speed distribution, near rated speed region.

Figure 4 includes hydraulically powered machines, where the diesel engine generates rotation to a hydraulic pump. Examples of these applications are some construction machines such as hydraulic excavators, road rollers, as well as agricultural machinery as hydrostatic sprayers, harvesters, etc.

Figure 5 is very specific for loaders, backhoes, related to its loading ability when working with a truck. (it means loading it).

Basically, off-road diesel engine applications that should comply with Brazilian offroad emissions standard (MAR-I), are shown in figures 3, 4 and 5. An optimization work of the trade-off between specific fuel consumption and emissions in the region of rated power speed would bring good results, also improving customer satisfaction for these applications, representing a large number and variety of machines on this work. For machines of Figure 5, they will have less benefit due to different operating range, with lower residence in the power speed region. 


\section{METHODOLOGY}

Quality of test cell DoE and Response Surface Model are fundamental for the accuracy of the methodology.

Quality $D o E=$ good engine repeatability and good control over factors and non factors.

Quality Response Surfaces $=$ adequate number of DoE points and proper model selection / evaluation.

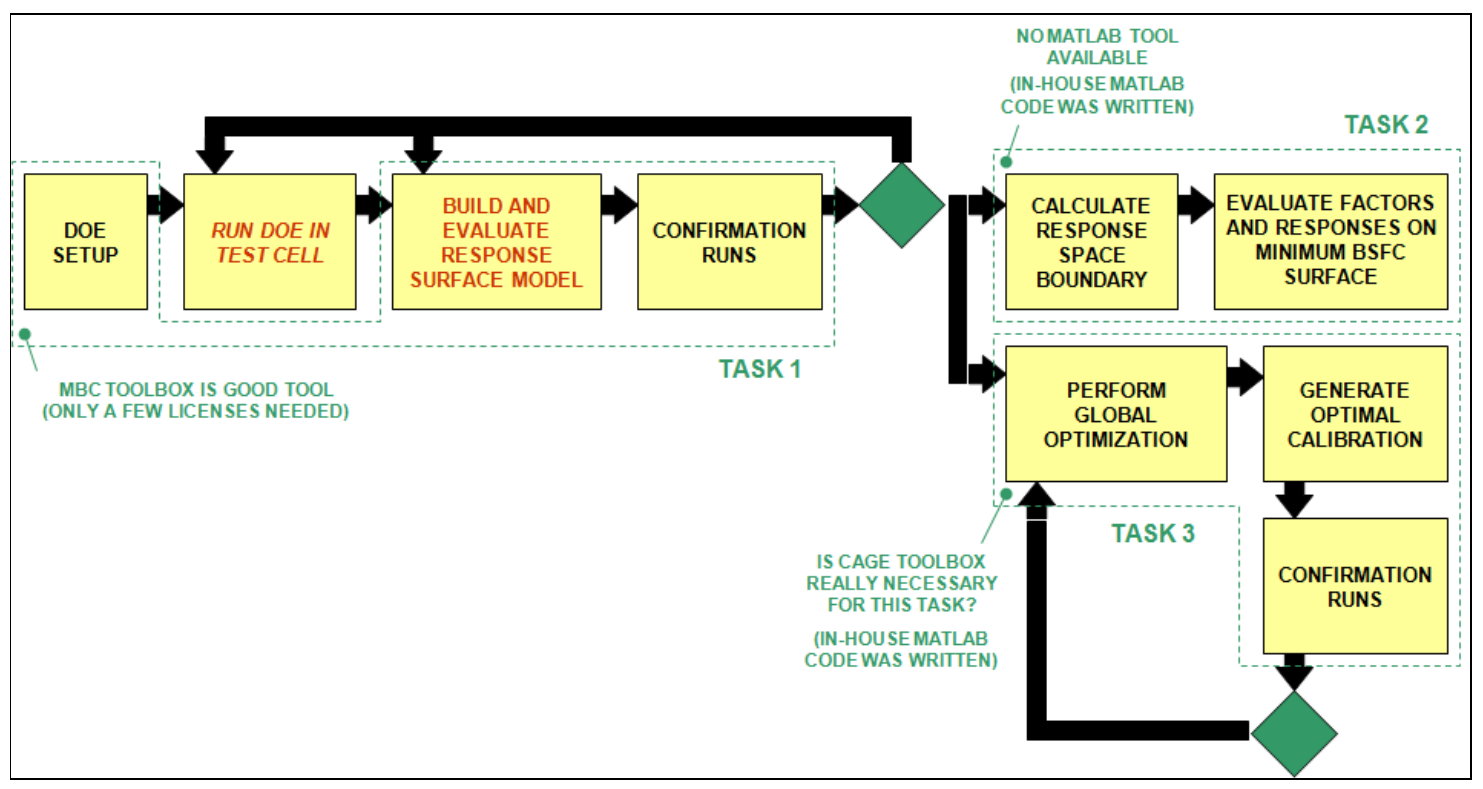

Figure 6: Combustion development process workflow.

\subsection{DoE - setup and response surface models (RSMs) - task 1}

The fundamental question is: How is the best representation of the engine behavior (through RSMs) with the least amount of test data?

Trade-off between number of DoE points and range of model accuracy.

Example: single variable (factor) curve fitting. 


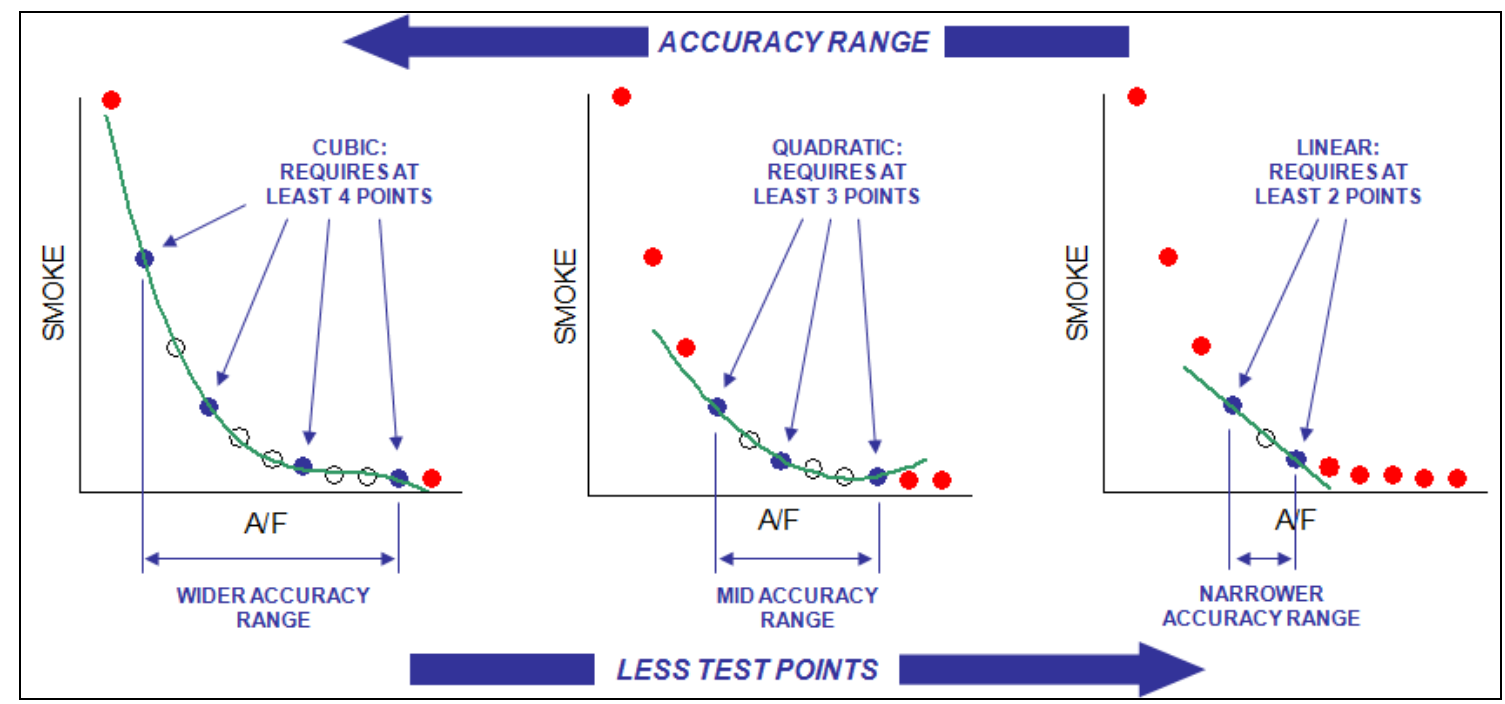

Figure 7: DoE setup and Response Surface Models (RSMs).

Traditionally, DoEs targeted to $2^{\text {nd }}$ order polynomial fitting, is used such as CCF.

Cube Center Face (CCF) and D-Optimal methods (with 3 factor levels) do not contain enough information for higher order polynomial fitting or more complex surface fitting such as Radial Basis Functions (RBFs) [4]

Two approaches are possible for more complex response behaviors:

- Divide the factor space in smaller sub-spaces so $2^{\text {nd }}$ order DoE methods become accurate (Local Technique).

- Use other DoE techniques (such as Space Fill) that contain more test points and therefore allow for the whole factor space to be analyzed at once (Global Technique).

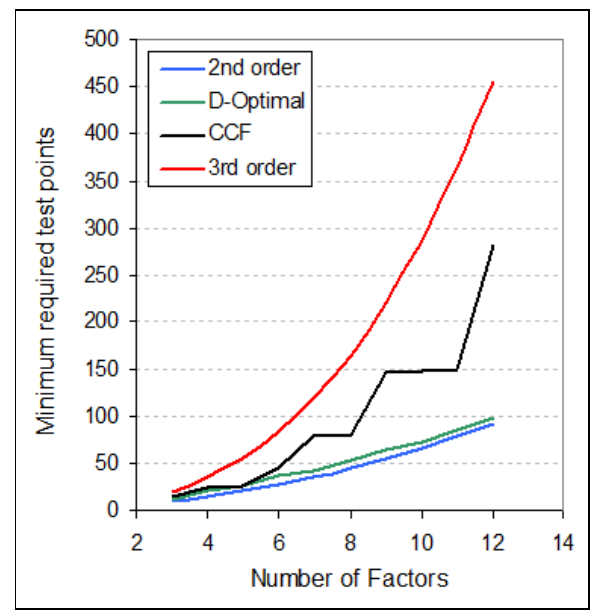

Figure 8: Types of approaches for more complex response behaviors.

Which approach (Local vs. Global) is recommended for engine testing?

As an example, considering a steady state calibration for the 8-Mode region (excluding low idle). The following 5 factors were chosen: 

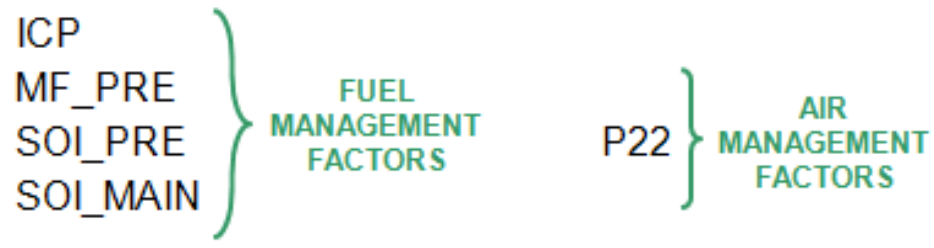

The local approach DoE with D-Optimal leads to 7 [Speed/Load points] x 32 [test points per mode] $=224$ test points.

The local approach DoE with CCF leads to 7 [Speed/Load points] x 52 [test points per mode $]=364$ test points.

The global approach with space fill and 7 factors (Speed and Load are added) leads to 303 to 463 test points (assuming 1.5 to 2 times the number of points required for $3^{\text {rd }}$ order polynomial).

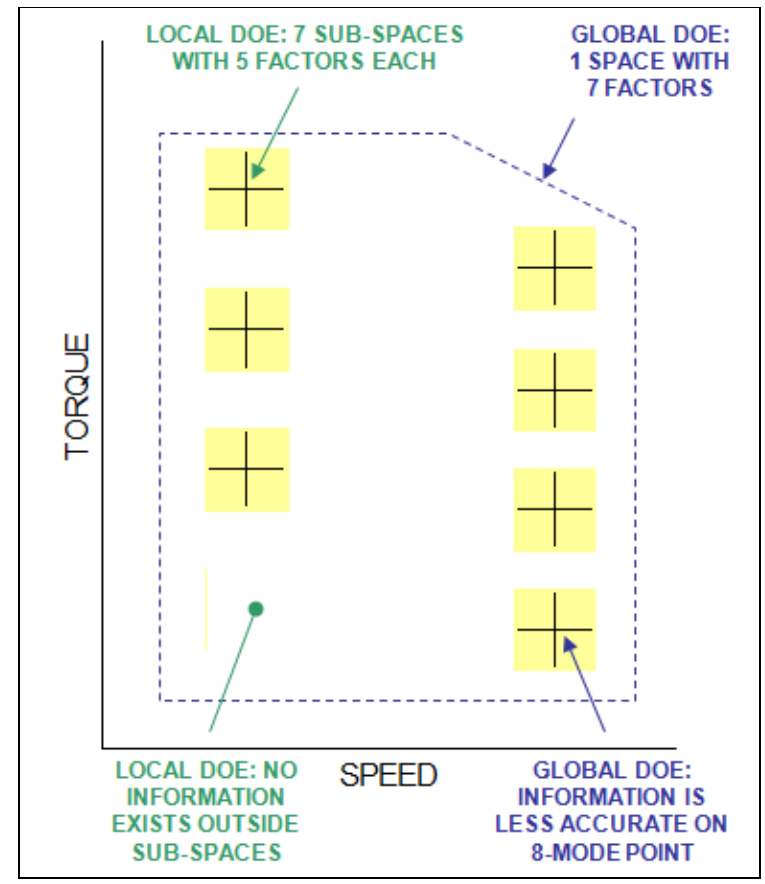

Figure 9: Optimized combustion: Local DoE \& Global DoE areas.

Which approach (Local vs. Global) is recommended for engine testing? It has to be determined for each particular situation taking into account the following pros and cons.

$\rightarrow$ First advantage of the Local DOE compared to the Global DoE is that engine behavior is more accurately captured at specific speed and loads, which may be important for the steady state emissions calibration.

$\rightarrow$ Second advantage of the Local DoE compared to the Global DoE is that test data becomes available in smaller usable blocks. There is, therefore, better alignment 
between testing and model construction. Additionally, test problems can be detected earlier.

$\rightarrow$ First disadvantage of the Local DoE compared to the Global DoE is that even the local behavior at a given 8-Mode speed and load point can be no more than quadratic. In other words, careful selection of the factor ranges should be made to ensure model accuracy. With the Global approach, more complex surface fitting can be done for all factors, thus wider factor ranges are possible.

$\rightarrow$ Second disadvantage of the Local DoE compared to the Global DoE is the required number of test points. For 7 factors, Local DOE requires 2.4 to 3.2 more points than Global DoE. (If D-Optimal is used, the ratio drops to 1.05 to 1.4 ).

Third disadvantage of the Local DoE compared to the Global DoE is that it cannot cover the entire speed and load map of the engine. Its calibration value is limited to the selected speed / load points.

\subsection{Response space and response space boundary - task 2}

It is possible to map any set of system responses (2, 3 or more) to the response space. This will prove to be a useful visualization method, since it is hard to visualize individual responses for more than 2 factors.

Since the factors are bounded, the response space is also bounded.

The region of the response space inside the boundary is the achievable region for the given factor ranges.

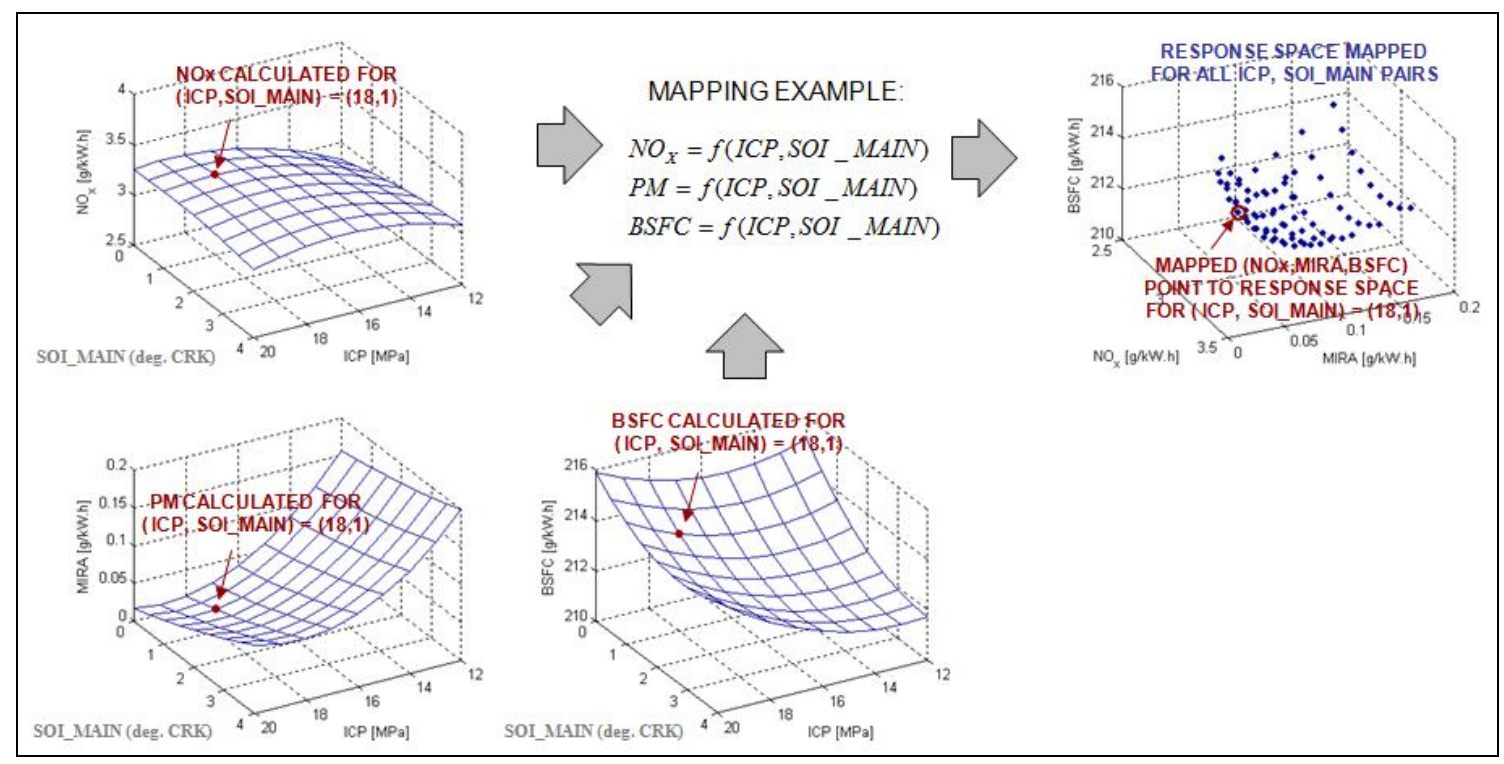

Figure 10: Response Space and Response Space Boundary.

In general, NOx, Particulate Matter (PM) and BSFC are important responses when calibrating an engine. 
Of particular interest is the minimum BSFC surface inside the achievable NOx / Particulate Matter (PM) region.

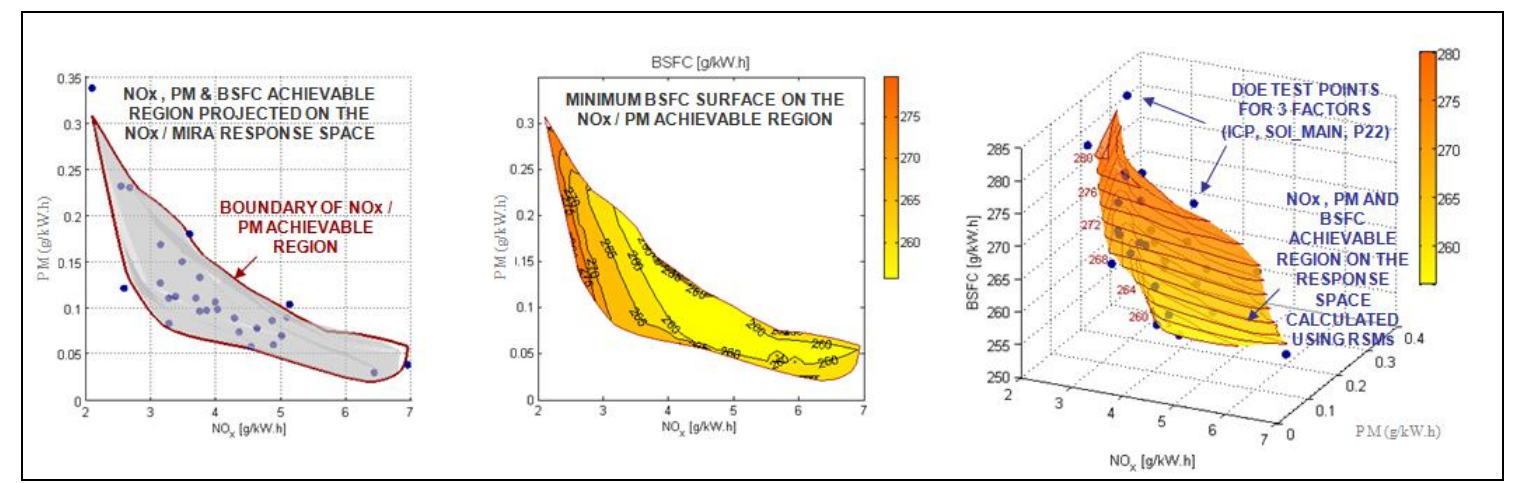

Figure 11: NOx, PM and BSFC achievable region on the response space calculated using RSMs.

Due to the mapping between factor and response spaces, the values of any factor at the minimum BSFC surface are known and can also be plotted in the NOx / Particulate Matter (PM) achievable region.

Since the factor values are known on the minimum BSFC surface, any other response which has an RSM can be calculated and also plotted in the NOx / Particulate Matter (PM) achievable region.

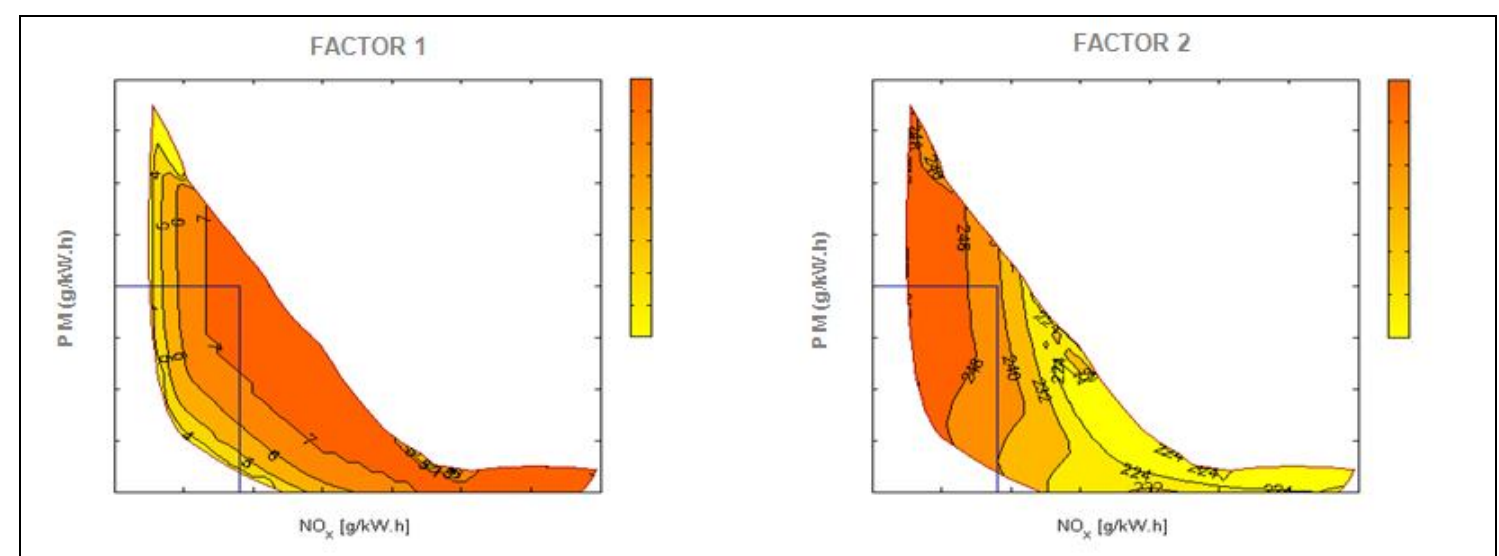

Figure 12: Minimum BSFC surface calculated in terms of NOx and PM

Different MATLAB routines were coded to generate the plots presented in TASK 2.

The routines use MATLAB pre-existing functions for optimization.

The steps required to achieve TASK 2 are grouped in individual MATLAB script files and are highly automated.

Little user input and some MATLAB knowledge is necessary for each step.

\subsubsection{Step 1: Calculation of boundary candidate points.}


The boundary is calculated in the NOx / PM space and uses a pre-existing multiobjective MATLAB optimization function (fgoalattainment).

The algorithm to determine the candidate points consists of a line-search method with multiple search directions starting from each one of the four corners of the domain.

Initial conditions for the algorithm cover the corners of factor space in order to assure global solutions and therefore the most external boundary candidates.

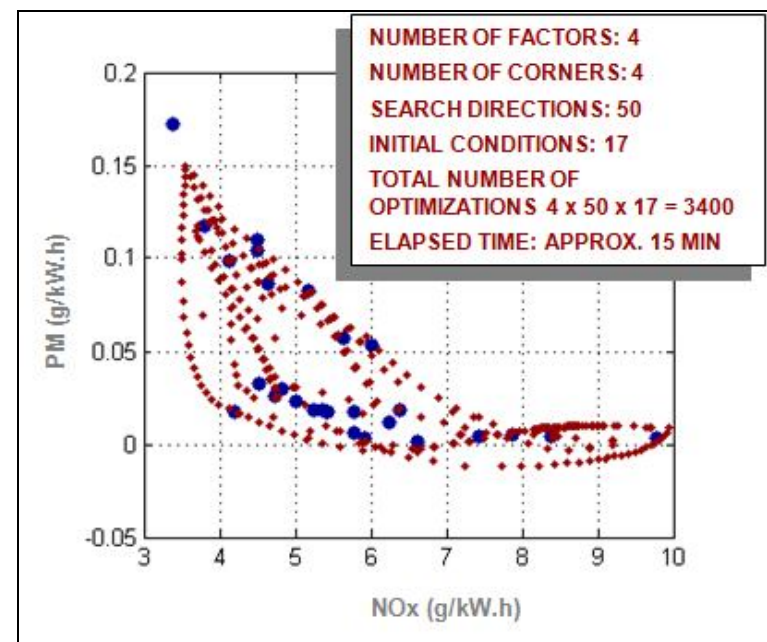

Figure 13: Calculation of boundary candidate points.

\subsubsection{Step 2: Selection of boundary points.}

Selection of most external boundary points is done with a specially developed moving circle algorithm.

The boundary points and their corresponding factors are exported to ASCII files.

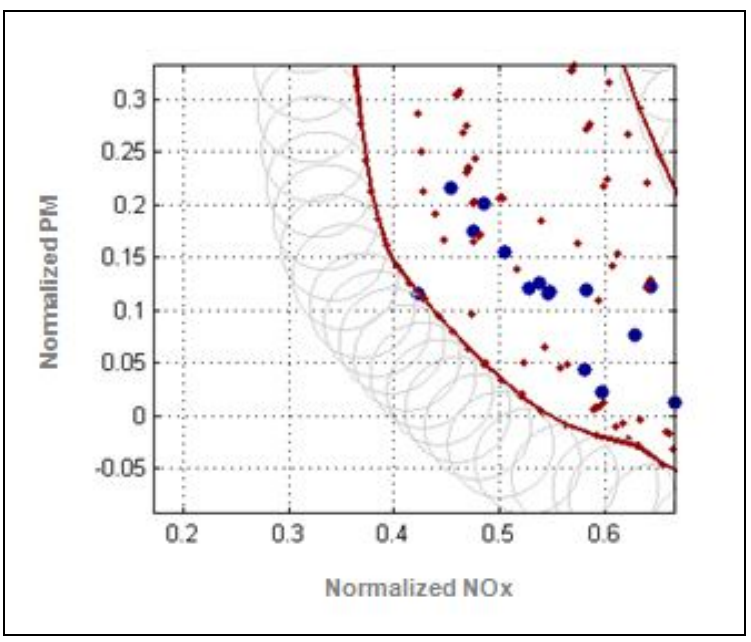

Figure 14: Selection of boundary points. 


\subsubsection{Step 3: Calculation of minimum BSFC}

A grid is defined and the points internal to the boundary are determined using a specially developed algorithm. A point is considered interior if the boundary is visible $360^{\circ}$ around that point.

Minimum BSFC is calculated using a pre-existing single-objective MATLAB optimization function (fmincon). BSFC is minimized for a given interior grid point having NOx and Particulate Matter (PM) constrained at the grid point value.

Initial conditions for the algorithm cover the corners of factor space in order to assure global minima.

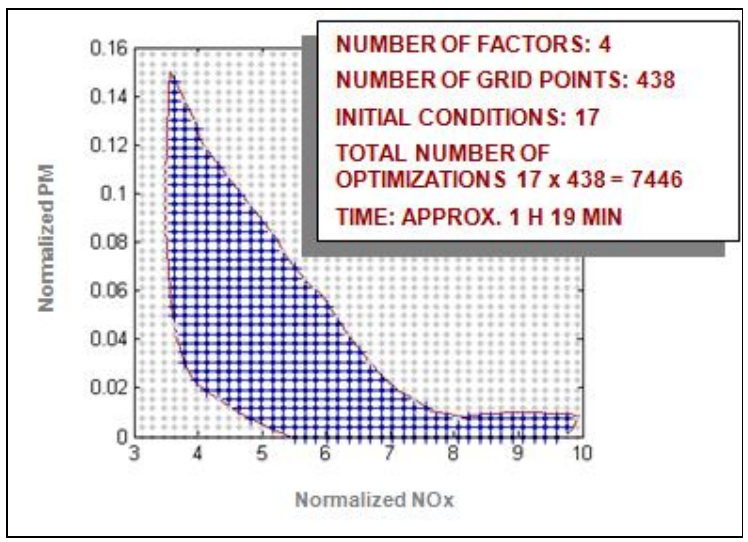

Figure 15: Calculation of minimum BSFC

\subsubsection{Step 4: Plotting results for minimum BSFC}

Any of the factors that produce the minimum BSFC surface can be plotted in the NOx / Particulate Matter (PM) achievable region.

Any response that has an RSM can be calculated as a function of the minimum BSFC factors and plotted in the NOx / Particulate Matter (PM) achievable region. 

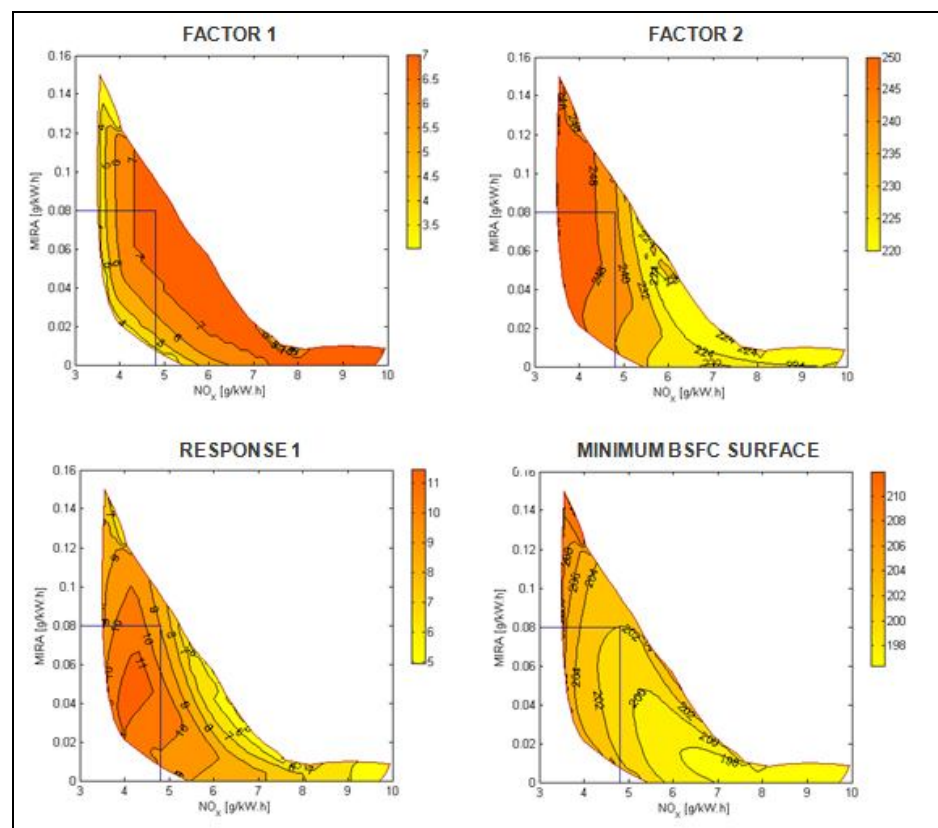

Figure 16: Plotting results for minimum BSFC

\subsection{Global optimization - task 3}

Once each local model of the global model is built and verified for accuracy it is possible to run a global optimization.

In general, BSFC has to be minimized for a given driving cycle, while composite NOx and Particulate Matter (PM) must be within the legal limits.

Additional responses may also constrain the optimization, such as maximum cylinder pressure or maximum exhaust temperature, among others.

For local DoE approach, a typical optimization setup would then be [2]:

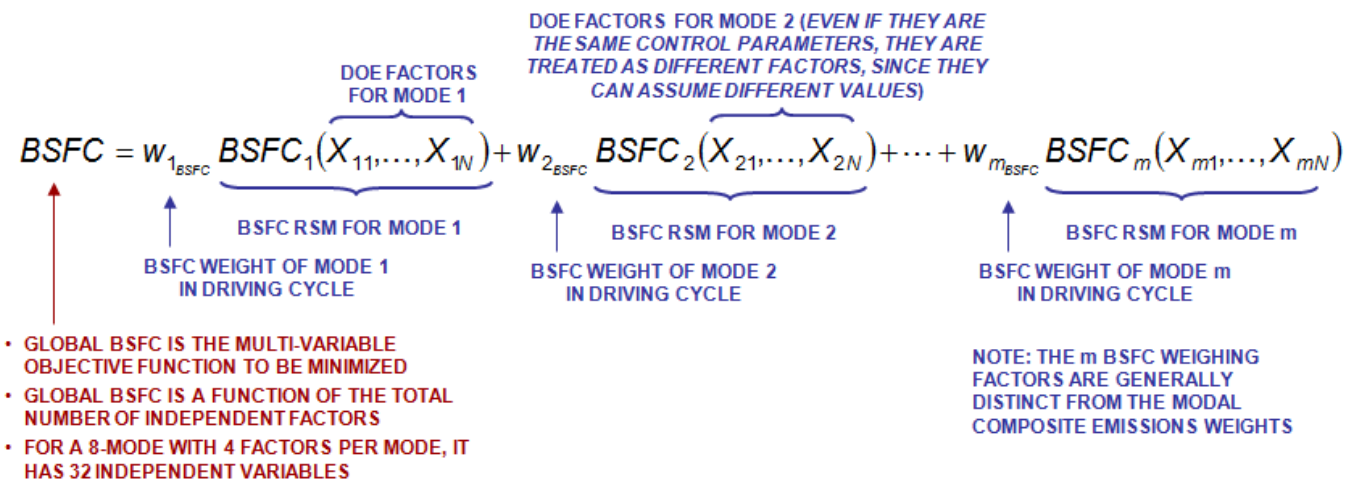




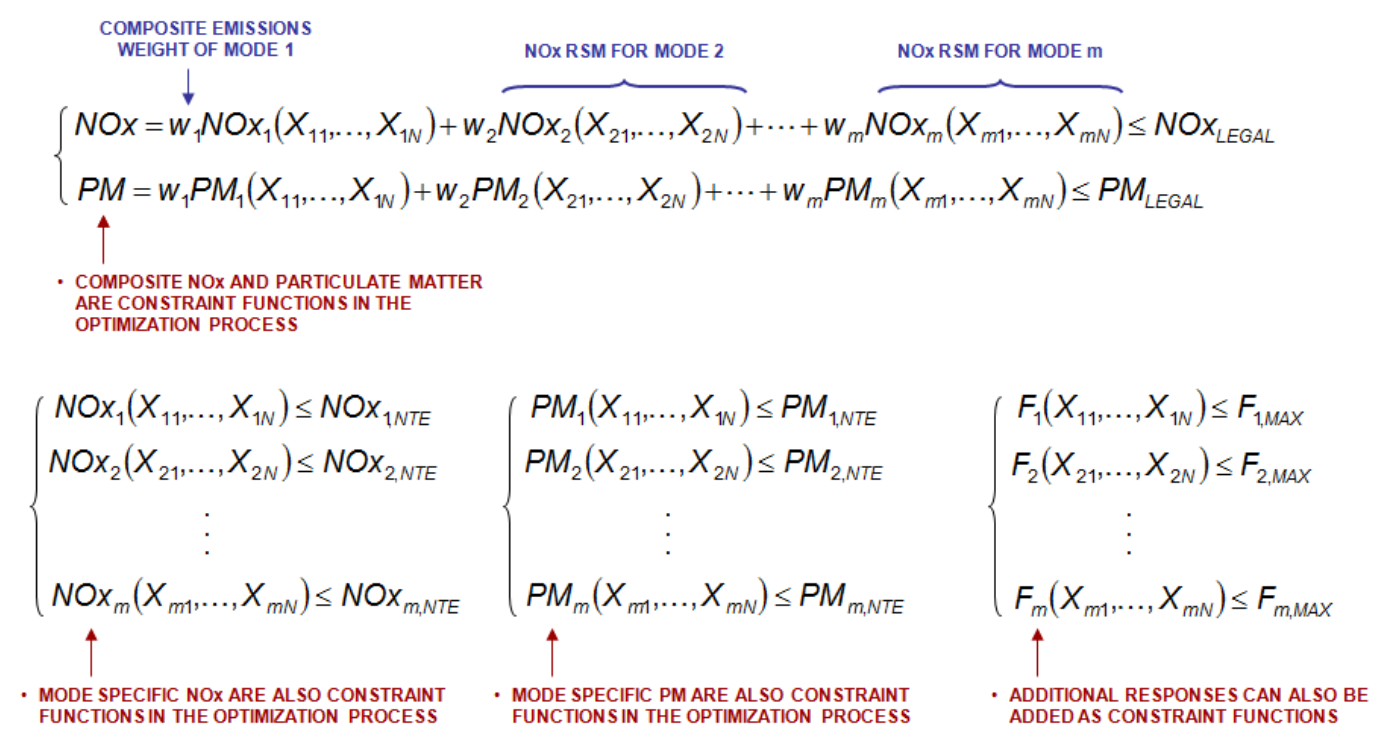

For global DOE approach, the main difference is that individual RSMs for each mode are not defined. For each response there is one single RSM which is a function of speed and load as well [3].

For example, the global BSFC function would be:

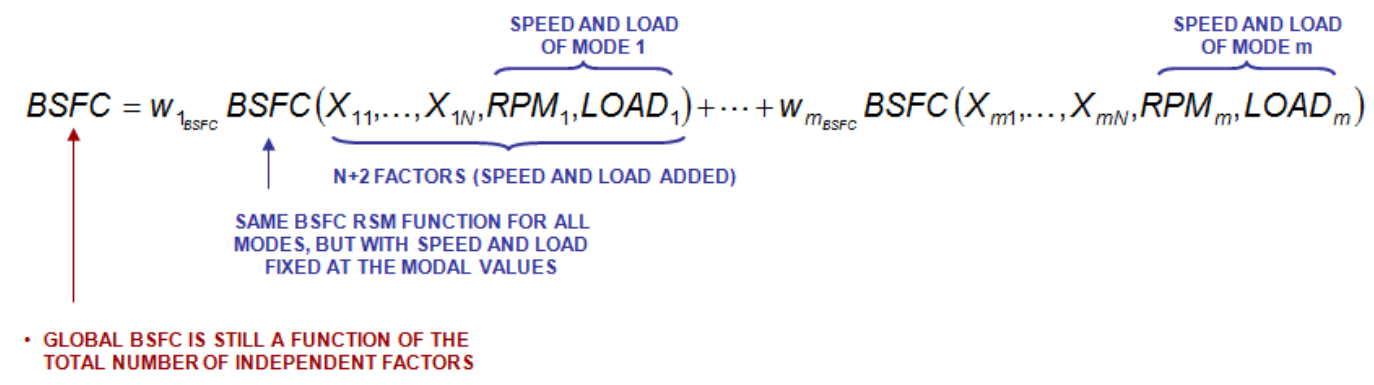

The constraint functions for NOx, Particulate Matter (PM) and any additional response follow the same principle as shown for the BSFC function.

Different MATLAB routines were coded to perform the optimization and generate optimal calibration.

The routines use MATLAB pre-existing functions for optimization.

Multiple initial conditions are used to assure global minimum is determined.

Statistical evaluation of the optimal factors is done to understand "quality" of the solution.

Currently, bilinear interpolation is used to generate calibration map on calibration break points. No method is yet defined for break points external to DoE region. 
Example: Optimal calibration for Diesel engine running typical Off-Road Cycle as shown in Figure 17.

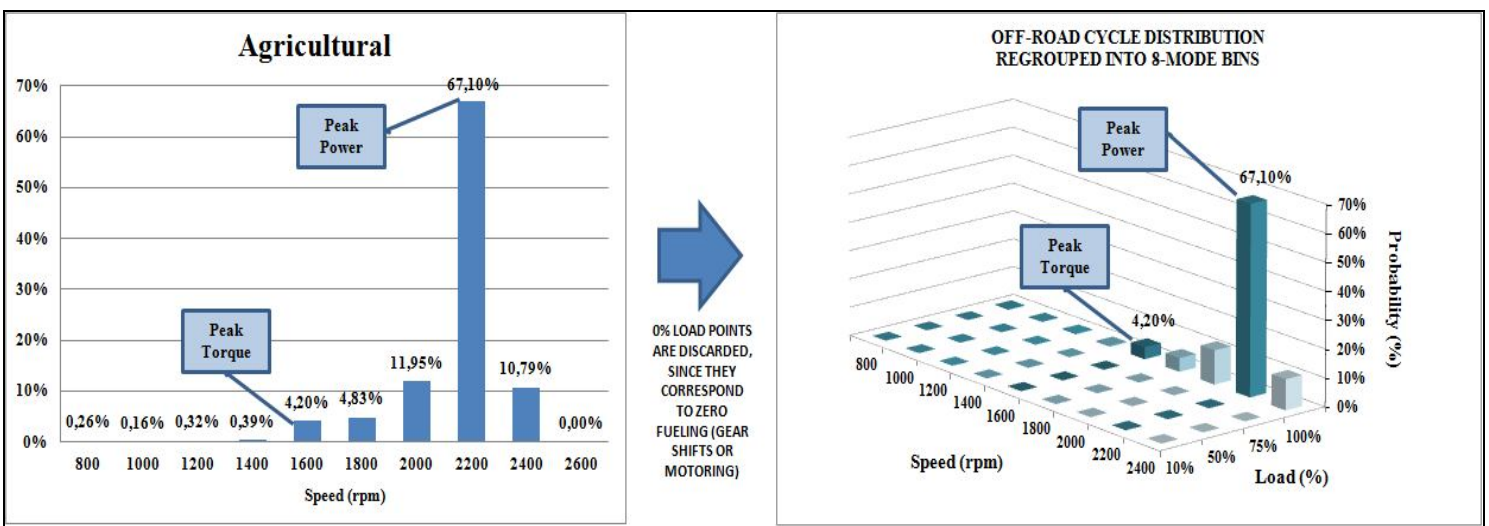

Figure 17: Typical Off-Road Cycle

With the typical Off-Road Cycle information, BSFC and emissions global functions have different weighing factors on the 8-Mode test points (Note that base calibration for idle condition was used, therefore, idle was not considered in this DoE / Optimization work).

Emissions weights become higher as one moves to the center speed and higher loads.

Off-Road Cycle (BSFC) weights are concentrated on the higher speed full load region as shown in Figure 18.

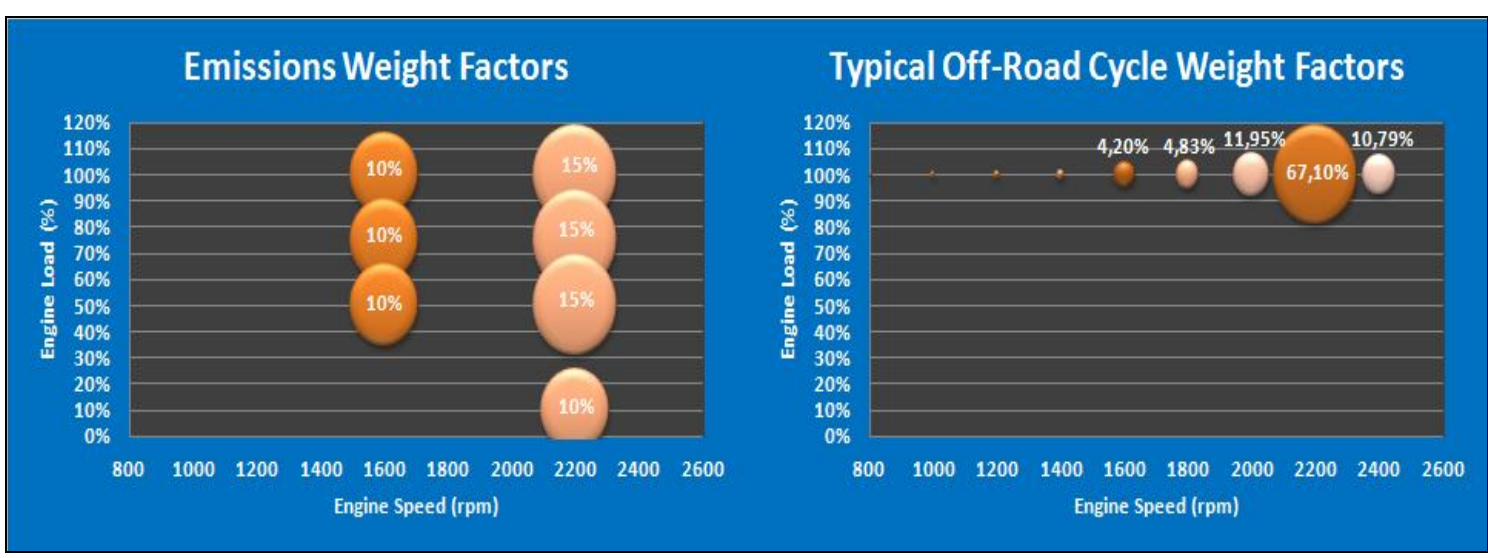

Figure 18: Emissions x typical off-road application weight factors

A space fill DoE was used to generate 100 initial conditions evenly distributed inside the 48 variable spaces of the global functions.

The number of initial conditions, variables and constraint functions make the optimization very CPU intensive. (About 8 minutes per initial condition and a total of approximately 13 hours to completion). 


\section{RESULTS}

During the development of the 6 cylinder engine, this methodology was applied to optimize the combustion calibration parameters, aiming to achieve legal emissions requirements with lowest fuel consumption. So for this work, the results of only one point are presented, which one is the most representative on off-road machine driving cycle and one of the highest weighting factor on 8-Mode emissions test cycle, this point is the rated power condition.

\subsection{DoE preparation}

For this work just two factors were chosen to be optimized, nevertheless both have big relevance on emissions and fuel consumption. The factors chosen were SOI_MAIN (start of main injection) and ICP (injection pressure), applying the DoE methodology on this work we have the following - see table 3:

\begin{tabular}{|c|c|}
\hline $\begin{array}{c}\text { SOI_MAIN } \\
\text { (deg. CRK) }\end{array}$ & $\begin{array}{c}\text { ICP } \\
\text { (MPa) }\end{array}$ \\
\hline-2 & 70 \\
\hline-2 & 70 \\
\hline-2 & 90 \\
\hline 0 & 70 \\
\hline-4 & 70 \\
\hline-2 & 50 \\
\hline-2 & 70 \\
\hline-4 & 90 \\
\hline-2 & 70 \\
\hline 0 & 90 \\
\hline 0 & 50 \\
\hline-2 & 70 \\
\hline-2 & 70 \\
\hline-4 & 50 \\
\hline
\end{tabular}

Table 3: DoE - Design of experiment.

The interaction between the factors described on table 3 were evaluated in bench test with the results obtained generating the buildup of statistics models for combustion of the chosen point.

\subsection{Local models}

The response surface of minimum fuel consumption (BSFC) was determined using the methodology described on the present work, based on SOI_MAIN and ICP factors. Figure 19 illustrate the best trade-off found between NOx and PM using this tool.

Figure 20 shows the NOx and MP responses as function of the factors behavior, the maximum and minimum values obtained on experiment are qualified in its respective scales and presented on the right side of the graphics. 


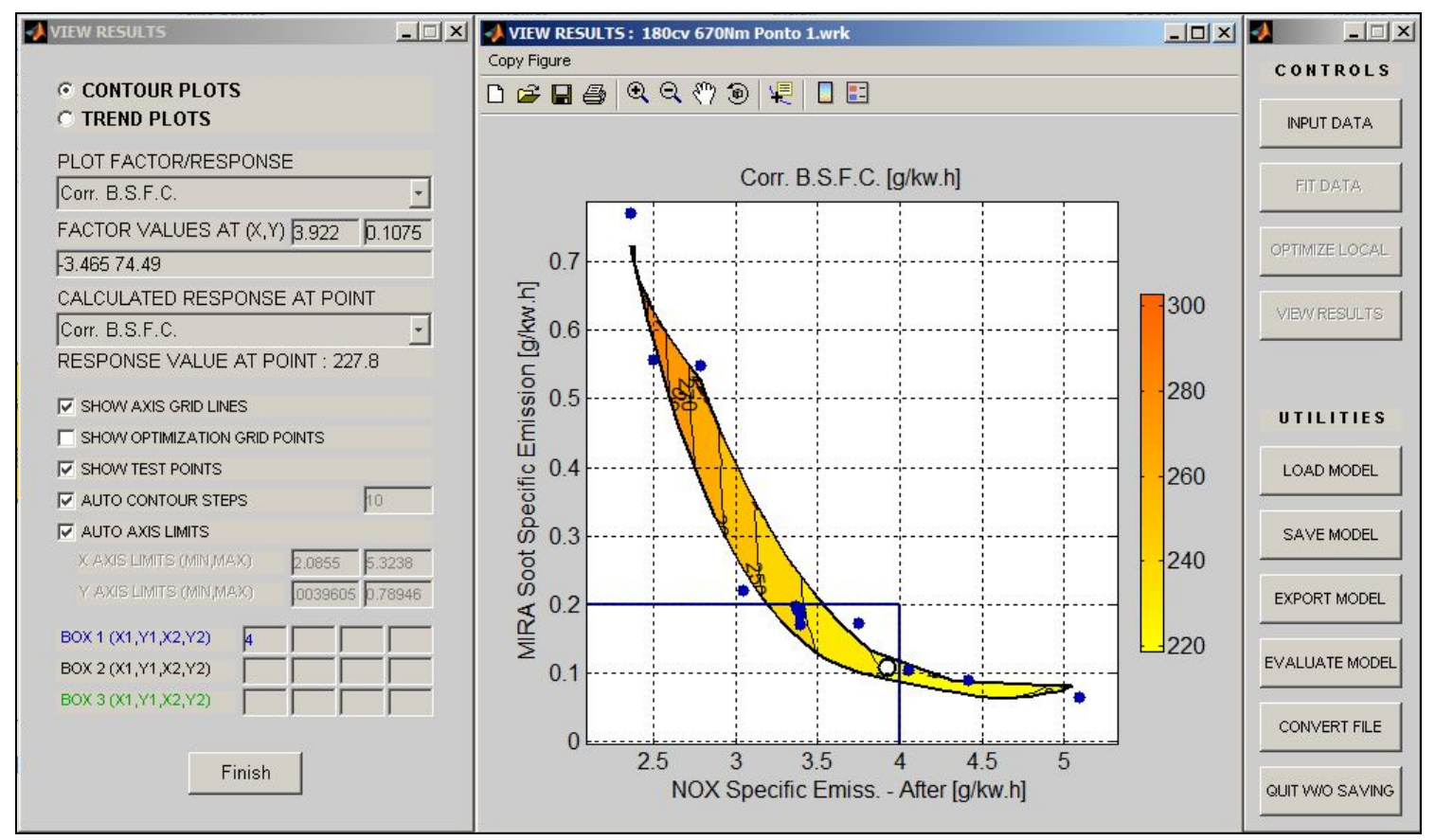

Figure 19: Calgen software screen - statistic models build up as function of pre selected factors

Graphical analysis of the Contour Plots, represents all the region cover by the experiment and must be utilized with the Response Surface analysis, as shown in Figure 20. Contour Plots are used to better exploit the best relation between three variables of a determined experiment, presenting the tridimensional ratio between the factors and response variables of an experiment. The $\mathrm{X}, \mathrm{Y}$ and $\mathrm{Z}$ axis can present both the factors as the response variables. This graphic type presents the behavior of the variable in study in $\mathrm{Z}$ axis as function of the plotted variables in $\mathrm{X}$ and $\mathrm{Y}$ as an isomap, the same as a topographic map where latitude, longitude and elevation are substitute by response variables.

The Countour Plot graphics can have yet 14 combinations presented as design of experiments matrix (blue points) used on surface build-up to help the comprehension of results, as Figure 19 illustrates. The blue rectangle presented in all Contour Plot graphics represent the values of NOx and PM targets, serving also as a reference for the researcher and been used as a guide on the definition of the best configuration of the evaluated factors.

Regarding the mode \#1 - full load point - in study, we must carefully consider the combustion pressure and exhaust temperature limits. So, the possible optimal combinations are in regions close to the rectangle tending to the right regions which present the best BSFC values without penalizing too much NOx and PM. 


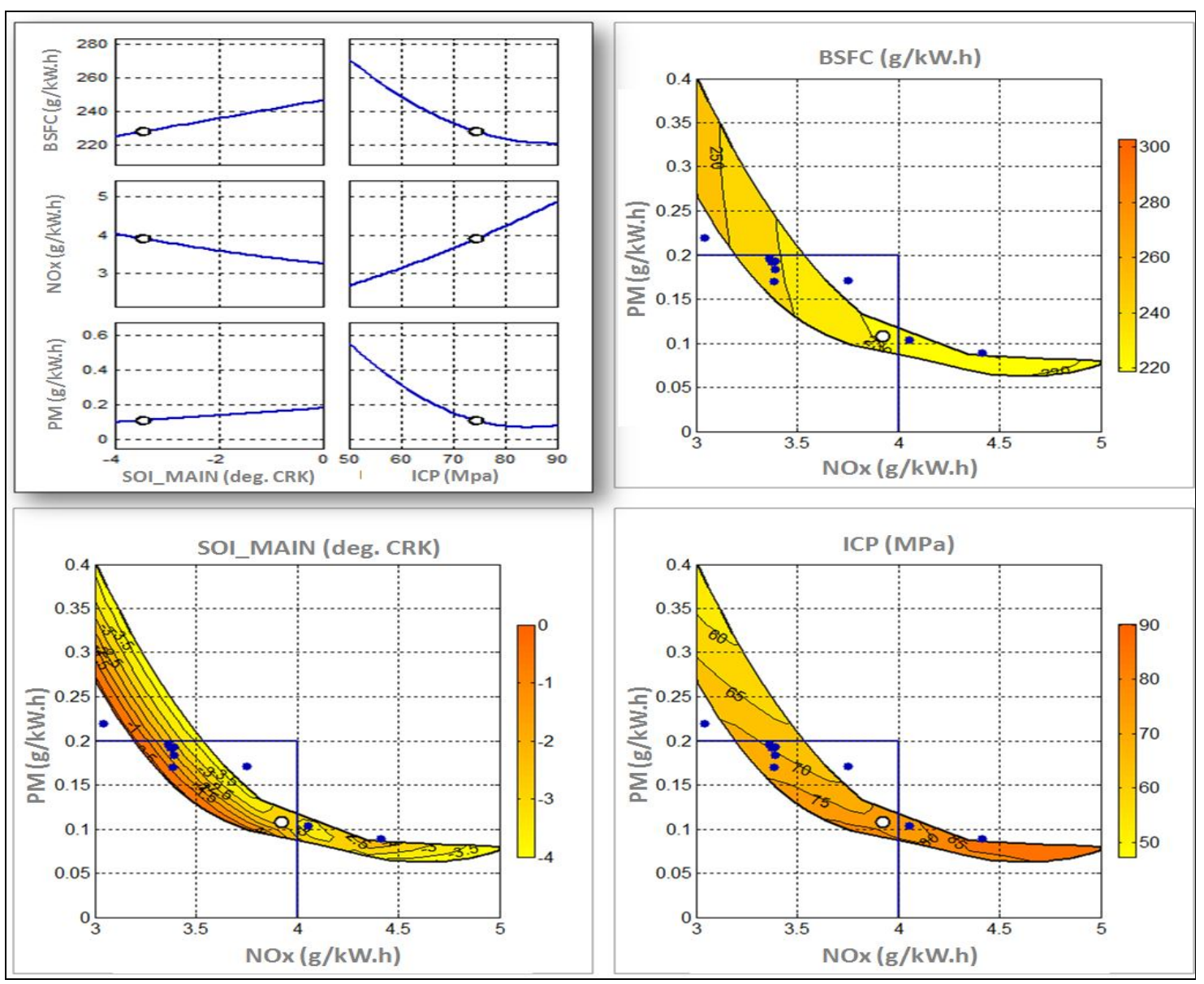

Figure 20: Minimum BSFC surface combined with each factor.

In the $\mathrm{Z}$ axis besides the factors, some variables of interest can be represented as combustion pressure and exhaust temperature, see Figure 21.

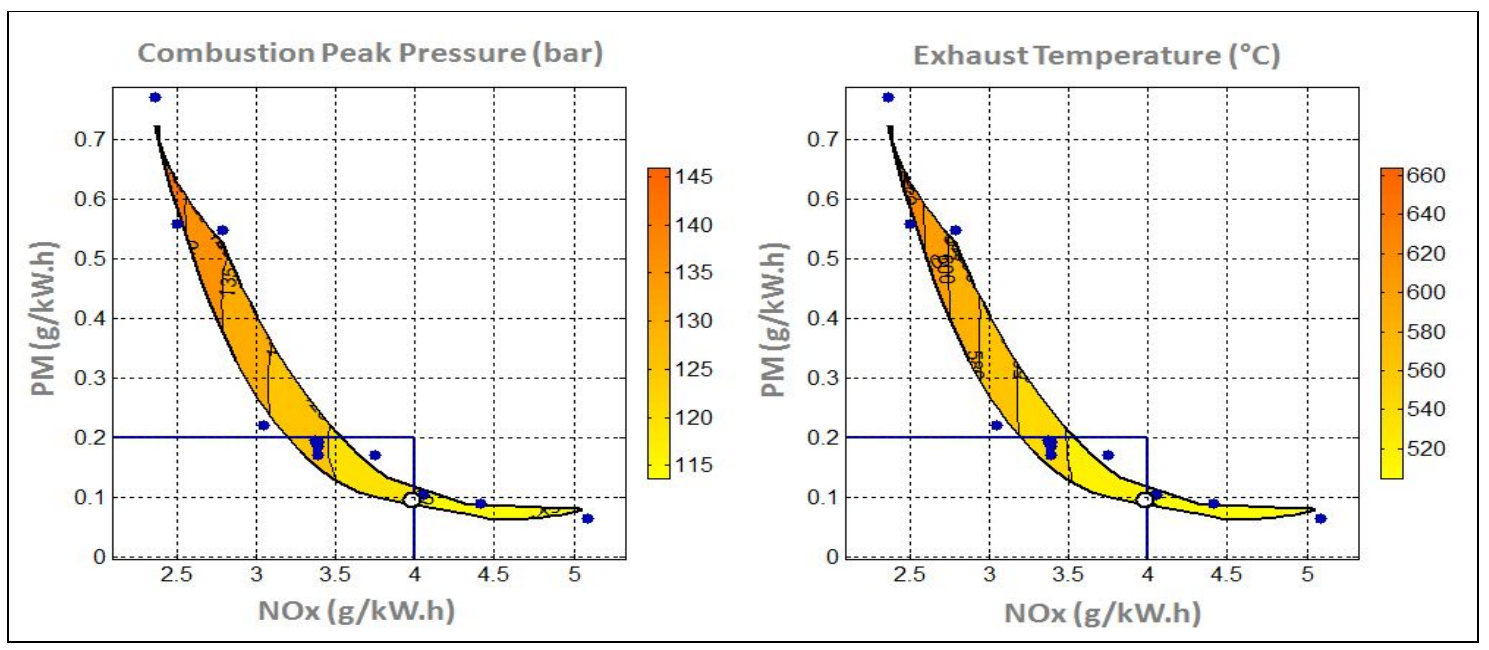

Figure 21: Response Optimizer. 


\subsection{Global model}

For the 8-mode cycle, after the end of punctual and graphical analysis of all the points contained in the cycle, the next step to be considered is the global analyzes which may be represented by 3D maps and exported directly to calibration software. The generated global optimizations correspond only to the region between the 8 points of 8-Mode cycle type C1 as shown in Table 2 and Figure 23.

The optimal factors that minimize BSFC for the typical off-road cycle and meet required emissions targets are:

\begin{tabular}{|c|c|c|c|c|c|c|}
\hline \multirow[b]{2}{*}{ Mode \# } & \multirow[b]{2}{*}{$\begin{array}{l}\text { Speed } \\
(\mathrm{rpm})\end{array}$} & \multirow[b]{2}{*}{$\begin{array}{c}\text { Load } \\
(\%)\end{array}$} & \multicolumn{2}{|c|}{ Optimal Factors } & \multicolumn{2}{|c|}{ Constrained Responses } \\
\hline & & & $\begin{array}{l}\text { SOI_MAIN } \\
\text { (deg.CRK) }\end{array}$ & $\begin{array}{l}\text { ICP } \\
(\mathrm{MPa})\end{array}$ & $\begin{array}{l}\text { Combustion Peak } \\
\text { Pressure }<180 \text { bar }\end{array}$ & \begin{tabular}{|c|} 
Exhaust \\
Temperature $<710^{\circ}$.
\end{tabular} \\
\hline 1 & 2200 & 100 & $-2,0$ & 71,0 & 124 & 550 \\
\hline 2 & 2200 & 75 & $-2,1$ & 50,0 & 103 & 507 \\
\hline 3 & 2200 & 50 & $-2,2$ & 40,0 & 82 & 438 \\
\hline 4 & 2200 & 10 & 1,0 & 35,0 & 48 & 266 \\
\hline 5 & 1600 & 100 & 0,0 & 45,0 & 102 & 578 \\
\hline 6 & 1600 & 75 & 0,0 & 37,5 & 87 & 529 \\
\hline 7 & 1600 & 50 & 0,0 & 35,0 & 71 & 434 \\
\hline 8 & - & Low Idle & - & - & - & - \\
\hline
\end{tabular}

\section{Table 4: Optimal factors and constrained responses}

Using the optimal factors and bilinear interpolation, it is possible to build the calibration maps inside the 8-Mode region, as shown in figure 23.

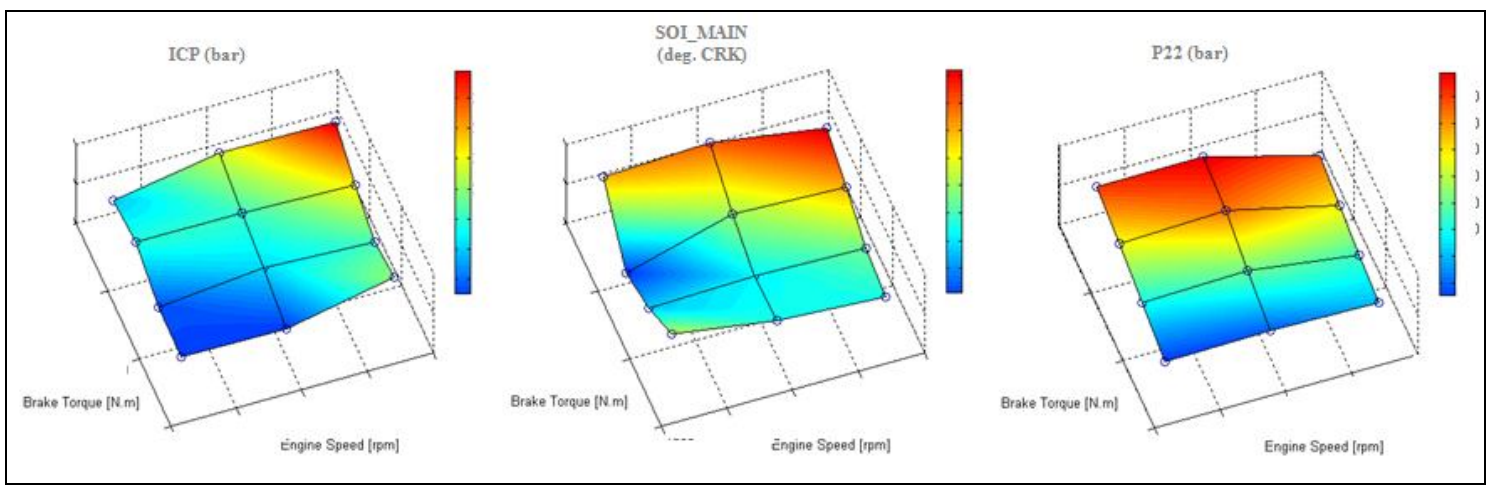

Figure 23: The optimal factors and bilinear interpolation to build the calibration maps inside the 8-Mode region.

\section{CONCLUSION}

The methodology presented in this study was very effective, it was possible to reduce the calibration development time by one third also maximizing the level of knowledge of the response variables and especially of the factors influencing them. The models built in this work can generate different calibration levels, they are easily adaptable, always respecting the trade-off emissions and fuel consumption, depending only on the driving cycle and/or application behavior.

After construction of the models, several off-line simulations can be performed, i.e., changing 
the factors levels and their impact in response variables, similar to a virtual dynamometer, so it is possible to reduce development time and costs.

\section{REFERENCES}

[1] DIESELNET. Available at: <www.dieselnet.com> searched on: May, $15^{\text {th }} 2015$.

[2] Myers, R. H. and Montgomery D. C. Response Surface Methodology. New York: John Wiley \& Sons, 1995.

[3] D. C. Montgomery. Design and Analysis of Experiments, Fifth Edition. New York: John Wiley \& Sons, 2001.

[4] VERLAG MODERNE INDUSTRIE. DoE - Design of Experiments - methods and applications in engine development. Berlin: IAV GmbH, 2005.

[5] International Organization for Standardization, International Standard- ISO 8178-1Reciprocating internal combustion engines -- Exhaust emission measurement -- Part 1: Test-bed measurement of gaseous and particulate exhaust emissions. ISO publication, 2006.

[6] Conselho Nacional do Meio Ambiente - CONAMA - Resolution 433/2011, CONAMA publication, 2011. 